\title{
Quality attributes for processing potato clones of purple-fleshed in Peru
}

\author{
Atributos de qualidade para o processamento industrial de clones de batata de polpa roxa \\ no Peru
}

\author{
Roberto Tirado Lara ${ }^{1 *}$ e Roberto Hugo Tirado Malaver ${ }^{2}$ \\ 1Universidad Nacional Pedro Ruíz Gallo, Lambayeque, Peru. *Autor para correspondência: tiradolararoberto@gmail.com. \\ ${ }^{2}$ Universidad Nacional José Faustino Sánchez Carrión, Huacho, Peru.
}

Submission:24/08/2018 / Acceptance: 01/07/2019

\begin{abstract}
There is an increase in the demand and consumption of potato crisps and french chips in Peru. Therefore, the objective of the present work was to evaluate the industrial quality parameters of the physical and chemical characteristics of 17 advanced potato clones with purple pulp and select the clones with the best responses to the attributes of quality for industrial processing in Cajamarca, Peru. The results showed that the clones exhibited acceptable physical characteristics (tuber shape, depth of the eye, skin color, and color of the pulp) for processing, including the Amarilis variety. In addition, the clones reported tuber sizes within the recommended range for chips $(40-60 \mathrm{~mm})$ and french fries $(\leq 45 \mathrm{~mm})$. Clone CIP302306.19 produced the highest content of dry matter of the tuber $(28.60 \%)$ and specific gravity $\left(1,106 \mathrm{~g} \mathrm{~cm}^{-3}\right)$, with low levels of reducing sugars $(0.062 \%)$ and an acceptable range for the processing of the chips, while the lowest dry matter content (19.39\%) and specific gravity $\left(1.072 \mathrm{~g} \mathrm{~cm}^{-3}\right)$, were reported by clone CIP302290.11. Most of the clones produced tubers with a dry matter content greater than $20 \%$ and a specific gravity greater than $0.080 \mathrm{~g} \mathrm{~cm}^{-3}$, in addition to low levels of reducing sugars, and they are within the acceptable range for chip processing. The study indicated that the tested clones could potentially be used for chip production because of their significant effects on processing parameters.
\end{abstract}

KEYWORDS: food-security crop, Solanum tuberosum L., pigmented flesh, acrylamide, antioxidative, activity.

\section{RESUMO}

Há um aumento na demanda de consumo de chips e batata frita no Perú. Portanto, o objetivo do presente trabalho foi avaliar os parâmetros de qualidade industrial das características físicas e químicas de 17 clones avançados de batata com polpa roxa e selecionar os clones com as melhores respostas aos atributos de qualidade para processamento industrial em Cajamarca, Perú. Os resultados mostraram que os clones exibiram características físicas aceitáveis (forma do tubérculo, profundidade do olho, cor da pele e cor da polpa) para processamento, incluindo a variedade Amarilis. Além disso, os clones mostraram tamanhos de tubérculos dentro do intervalo recomendado para batata chips $(40-60 \mathrm{~mm})$ e batata frita ( $\leq$ $45 \mathrm{~mm})$. O clone CIP302306.19 produziu o maior teor de matéria seca de tubérculo $(28,60 \%)$ e gravidade específica $\left(1,106 \mathrm{~g} \mathrm{~cm}^{-3}\right)$, com baixos níveis de açúcares redutores $(0,062 \%)$ e uma faixa aceitável para 0 processamento dos chips, enquanto o menor teor de matéria seca (19,39\%) e a gravidade específica $\left(1,072 \mathrm{~g} \mathrm{~cm}^{-3}\right)$ foram relatados pelo clone CIP302290.11. A maioria dos clones produziu tubérculos com um teor de matéria seca superior a $20 \%$ e uma gravidade específica maior que $0,080 \mathrm{~g} \mathrm{~cm}^{-3}$, além de baixos níveis de açúcares redutores que estão dentro da faixa aceitável para processamento de chips. $O$ estudo indicou que os clones testados podem potencialmente ser usados para a produção de chips devido aos seus efeitos significativos nos parâmetros de processamento.

PALAVRAS-CHAVE: cultura de segurança alimentar, Solanum tuberosum L., polpa pigmentada, Acrilamida, Atividade antioxidante.

\section{INTRODUCTION}

Potato (Solanum tuberosum L.) is a vital food-safety crop and substitute for cereal crops considering its high yield and great nutritive value (ZHANG et al. 2017). Unlike the yellow and white potatoes, the potatoes with pigmented flesh have significant amounts important phytonutrients such as phenolic 
compounds (KITA et al. 2015). Recently, potato phenolic compounds have been recognized for their contributions to health, as they have been shown to have strong antioxidative activity (MORI et al. 2010). Considering that no significant difference between the phenolic content in fried samples and fresh samples has been detected, however, after the cooking process, total phenolics and flavonols increase, while the contents of vitamin $\mathrm{C}$, carotenoids, lycopene and anthocyanin decrease at a rate depending on the cooking method (ARKOUB 2016). Due to the high consumption levels of potatoes around the world, selected native Andean potatoes with pigmented flesh could be introduced into the market to deliver significant amounts of phenolic compounds with potential health-promoting properties into the human diet (GIUSTI et al. 2014).

On the other hand, potato varieties in Peru were developed to increase their yield leaving aside quality attributes for the processing industry, being an aspect that limits their acceptance for consumption of crisps and french fries. This negative characteristic means that the producers that supply the consumer markets for the potato processing industry are prone to losses, and they are not economically competitive, which allows the importation of processed potatoes to satisfy consumer demand. PEDRESCHI et al. (2016) mention that the potato processing industry mainly comprises cooked potatoes, par-fried potato strips, french fries, potato chips, potato starch, potato granules, potato flakes, and dehydrated diced potatoes, among others, that is, there is a wide variety of products. However, potato chips still continue to be the most popular processed product among consumers. The major challenge facing the industries lies in arranging round the year supply of processing varieties at reasonable price for their uninterrupted operation (MARWAHA et al. 2010). Crisps quality is influenced by different chemical and physical characteristics. These characteristics depend on cultural practices, environmental conditions, and genotype (OOKO \& KABIRA 2011). However, the genetic component has the strongest influence since the traits are heritable (KABIRA \& LEMAGA 2006).

The acceptability of potatoes for processing as french fries is largely dependent on the quality of the end products. The processing industry is totally dependent on the quality parameters of tuber to satisfy the increasing demand of customers (ABBAS et al. 2012). The excellence of processed foodstuffs based on tubers is mainly subjected by quality characteristics like tuber shape, dry matter, specific gravity, reducing sugar, and color, appropriateness of these parameters is indispensable for evaluation of potato genotypes for processing industries (ZAMAN et al. 2016).

There are two important parameters that are used to determine tuber quality for processing, both external (tuber size, skin color, color flesh, and eye depth) internal (dry matter content, specific gravity, and levels of reducing sugars) traits (ABONG et al. 2010).

To make the production cost-effective, the french fries industry acquire tubers with high dry matter content due to weight losses during frying in the form of vapor (ABU-ZINADA \& MOUSA 2015). The reducing sugars play a critical role in determining the color of fried products (BANDANA et al. 2016). FREITAS et al. (2012) indicate that chip color was most correlated with reducing sugar concentration. High reducing sugars content of tubers is responsible for browning during cooking and processing of potato chips and production of acrylamide (HALFORD et al. 2012). Acrylamide is a toxic and potentially carcinogenic chemical, it was assumed that the mechanism leading to the formation of acrylamide derived from Maillard reaction, i.e. the reaction between reducing sugars (glucose and fructose) and proteins/amino acids, also, acrylamide is a substance that is produced naturally in foods as a result of high-temperature cooking like baking, grilling, frying (THOMAS \& THOMAS 2014).

Therefore, the objective of the present work was to (i) evaluate the industrial quality parameters of the physical and chemical characteristics of seventeen advanced potato clones with purple pulp and (ii) select the clones with the best responses to the attributes of quality for industrial processing in Cajamarca, Peru.

\section{MATERIAL AND METHODS}

The present work was carried out in the experimental area of the locality of Llama located at 6030'14.65" of south latitude, at 7903'29.94" of west longitude and at an altitude of 2746 meters above sea level, in the department of Cajamarca, Peru, during the 2017 agricultural campaign. In the locality where the evaluation was carried out, it presented a loamy clayey loam textured soil, with an organic matter of $2.63 \%$, annual precipitation of $825 \mathrm{~mm}$, and a pH of 6.3.

\section{Field phase}

An experimental design of randomized complete blocks with three repetitions was performed. The experimental plot was 30 plants ( 3 rows of 10 plants each), is considered the central groove for the evaluations. The distance between rows and between plants was $1 \mathrm{~m} \times 30 \mathrm{~cm}$.

\section{Laboratory phase}

The determinations of the characteristics of this phase were carried out in the laboratory of the 
Department of Genetic Improvement of the International Potato Center (CIP), Lima. Tubers were selected free of physical and pathogenic damages, which were sheltered and identified. Subsequently, the genetic material was subjected to physical and chemical evaluation to determine industrial quality.

\section{Vegetal material}

Seventeen improved advanced purple pulp clones from the International Potato Center were evaluated: "CIP 302288.14, CIP 302306.36, CIP 302285.31, CIP 302288.39, CIP 302290.23, CIP 302288.33, CIP 302295.32, CIP 302278.28, CIP 302288.35, CIP 302304.27, CIP 302306.19, CIP 302281.15, CIP 302289.41, CIP 302280.23, CIP 302285.27, CIP 302288.42, CIP 302290.11", and a commercial variety "Amarilis INIA".

\section{Quantitative chemical parameters for industrial quality}

Reducing sugars: They were determined by the technique of TING (1956) cited by MARWAHA et al. (2010) with certain modifications. A $0.1 \mathrm{~g}$ sample of lyophilized potato pulp was added with $10 \mathrm{ml}$ of $80 \%$ ethanol, then refluxed for 1 hour at $80^{\circ} \mathrm{C}$, shaking every 10 minutes, filtered with filter paper No. 1 and it was completed by volume in aliquots of $25 \mathrm{ml}$ with $80 \%$ ethanol, $1 \mathrm{ml}$ of the dilution $+5 \mathrm{ml}$ of alkaline ferricyanide was taken, it is heated in a water bath for 30 minutes, then it is allowed to cool and $10 \mathrm{ml}$ of sulfuric acid is added making a slight stir until the gases are released and $4 \mathrm{ml}$ of Nelson's reagent is added, later read in the spectrophotometer at $745 \mathrm{~nm}$.

\section{Quantitative physical parameters for industrial quality}

Tuber size: Ten representative tubers were randomly selected for each potato clone and physically measured using a hand-held gauge. Tubers of size 40-60 $\mathrm{mm}$ in diameter were considered suitable for processing (ABONG et al. 2010).

Dry matter: It was determined by drying the tubers from five plants of the central groove of each block, then cut into slices, weighed (initial weight), and then placed in a stove for 72 hours. Temperatures of $80{ }^{\circ} \mathrm{C}$, then weighted again and determined the percentage of dry matter. Finally an average of each clone was obtained. The percentage of dry matter was obtained by the following formula:

MS $(\%)=($ final weight/initial weight $) \times 100$

Specific gravity: This characteristic was determined by the method based on the principle of Archimedes, weighing the tubers in the air compared to the weight of them in a volume of water, from five plants of the central groove of each block. The data was adjusted to the following formula:

$\mathrm{Ge}=$ Weight in the air of the tubers/(weight in air-weight in water)

Color of chip: They were cut into flakes, placed in a metal basket to boil with hot oil; at a temperature of $180{ }^{\circ} \mathrm{C}$, for $2.5 \mathrm{~min}$. The color of french fries will be assigned, on the subjective scale of colors, of the International Center of the Potato, being: (1): White or creamy yellow, (2): White or creamy yellow with very low presence of dark spots, (3): Creamy yellow with low presence of dark spots, (4): Creamy yellow with a tendency to darken and (5): Totally dark.

\section{Quantitative physical parameters for industrial quality}

The physical tuber parameters (shape, skin and flesh color, and eye depth) were determined according to the methods described by ABONG et al. (2010).

Tuber shape and eye depth: For 10 representative tubers, shapes were determined by observing the shape that was designated as round, elongated, oblong, long oval, pointed oval, or oval. The samples were measured for size and eye depths using a vernier caliper and a ruler, respectively. Size was determined in terms of diameter. Eye depth was recorded as shallow $(0.00-0.20 \mathrm{~mm})$, medium $(0.20-0.50 \mathrm{~mm})$, or deep $(>0.60 \mathrm{~mm})$.

Skin and flesh color: Five representative tubers were picked at random from a net bag of $10 \mathrm{~kg}$ of each variety and visually examined for skin color which was recorded as cream, red, white-cream, purple or blackish and flesh color which was recorded as cream, white-purple, cream-purple, purple, dark-purple, blackish, each tuber was then longitudinally cut with a knife and flesh colors recorded as white, yellow or cream (ABONG et al. 2010).

Data processing and statistical analysis were performed using the statistical package Statistical Analysis System, version 9.3 (SAS Institute, Cary, North Carolina, USA). The significance of the data was tested through analysis of variance at $p<0.01$ and $p<0.05$, the means were compared by Duncan test at a $95 \%$ confidence interval.

\section{RESULTS AND DISCUSSION}


The physical tuber characteristics such as tuber shape, skin, and flesh color, and eye depth are shown in Table 1. Great importance is given to tuber shape, eye depth, and general appearance. Consumers like potatoes of attractive look, suitable shape, size, and shallow to medium eyes to avoid peeling losses (ABBAS et al. 2012).

Table 1. Physical tuber quality characteristics of the different advanced potato clones of purple-fleshed.

\begin{tabular}{lllll}
\hline Clone & Shape & Skin & Flesh & Eye depth \\
\hline CIP 302288.14 & Long-oblong & White-cream & Purple & Shallow \\
CIP 302306.36 & Long-oblong & Purple & White-Purple & Medium \\
CIP 302285.31 & Long-oblong & Blackish & Cream-purple & Shallow \\
CIP 302288.39 & Rounded & Purple & White-purple & Deep \\
CIP 302290.23 & Long-oblong & White-cream & Purple & Shallow \\
CIP 302288.33 & Rounded & Purple & Yellow-purple & Deep \\
CIP 302295.32 & Long-oblong & Purplish-red & Purple-white & Slightly deep \\
CIP 302278.28 & Rounded & Blackish & Purple & Medium \\
CIP 302288.35 & Rounded & Purple & Yellow-purple & Deep \\
CIP 302304.27 & Rounded & Blackish & Purple & Deep \\
CIP 302306.19 & Rounded & Blackish & Cream-purple & Shallow \\
CIP 302281.15 & Long-oblong & Blackish & Cream-purple & Shallow \\
CIP 302289.41 & Rounded & Blackish & Purple & Deep \\
CIP 302280.23 & Rounded & Blackish & Purple & Medium \\
CIP 302285.27 & Oblong & Blackish & White-Purple & Deep \\
CIP 302288.42 & Rounded & Purple & Cream-purple & Deep \\
CIP 302290.11 & Rounded & Purple & Purple & Deep \\
Amarilis INIA & Rounded & White-cream & Cream & Deep \\
\hline
\end{tabular}

Tuber shape and eye depth: Tuber shape and eye depth of potatoes are important characteristics in influencing peeling and trimming efficiency during processing (ABONG et al. 2010). Tuber shape is a characteristic controlled by the genetic factors, and the environment may also affect it to some extent (ABBAS et al. 2012). Most of the clones had rounded shaped tubers and deep eyes except for two clones, the clone CIP 302306.19 with shallow eyes and clone CIP 302278.28 with medium eyes depth, both round tubers. Similar results presented by LI et al. (2005), who studied the inheritance and genetic mapping of tuber eye depth in potatoes, showed that the deep eye (Eyd) phenotype was found to be associated with round tubers (Ro) in most progeny clones. Based on shape, the cultivars with round shape have the potential to be processed to crisps that conformed to specifications (ABONG et al. 2010).

The clones CIP 302288.14, CIP 302285.31, CIP 302290.23, and CIP 302281.15 had long-oblong tubers and shallow eyes. CIP 302306.36 had long-oblong tuber and medium eyes, and the clone CIP 302295.32 had long-oblong tuber and eyes slightly deep. The long-oblong tubers, however, lend themselves easily for processing of french fries (ABONG et al. 2010). The clone CIP 302285.27 had oblong tuber and eyes deep. Oval or oblong shape tubers are preferred for making chips and french fries (ABBAS et al. 2012).

For the selection by parameters of industrial quality, MARWAHA et al. (2010) indicate that the shape, size, and depth of eyes: For making chips of uniform size, the tubers should be round to oval in shape. For french fries, oblong to long tubers are preferred, while for flakes, though round to oval shape is desirable, the requirement of shape is not very strict. For canning, small tubers of round to oval shape are suitable. Medium to large-sized tubers with shallow eyes are preferred for most of the processed products as these results in lower peeling losses (MARWAHA et al. 2010).

Color of skin and flesh: The color of skin and flesh is controlled by genetic factors (ABBAS et al. 2012). ZHANG et al. (2009) consider that pigmented tuber flesh is conferred by the Pf locus, and it is tightly linked with I locus, which is required for pigmentation of tuber skin, and it is presumably located on chromosome 10.

The clones CIP 302278.28, CIP 302304.27, CIP 302289.41, and CIP 302280.23 had blackish tuber skin and purple tuber flesh. These clones were heavily pigmented. Also, the clones CIP 302285.31, CIP 302306.19, and CIP 302281.15, which had blackish tuber skin but with cream-purple flesh, the clone CIP 302285.27 also had blackish skin and partially colored (white-purple) tuber flesh. The clones CIP 302306.36 
and CIP 302288.39, which have purple skin and white-purple tuber flesh, while the clones CIP 302288.33 and CIP 302288.35 had purple skin and yellow-purple tuber flesh, and the clone CIP 302290.11 had purple skin and flesh. The clone CIP 302288.42 had purple skin and cream-purple tuber flesh. CIP 302295.32, which has purplish-red skin and purple-white flesh. The clones CIP 302288.14 and CIP 302290.23, which had white-cream skin and purple flesh. Finally, the witness Amarilis INIA had white-cream skin and cream tuber flesh.

\section{Chemical tuber characteristics}

Potatoes having optimum dry matter, specific gravity, reducing sugars, good color are preferred by the processing industry (SOLAIMAN et al. 2015).

Tuber size: Tuber size directly influences crisp size, which in turn influences post-frying handling (ABONG et al. 2010). The analysis of variance of the mean squares detected differences significantly $(p<0.01$ ), ranging from $48.70 \mathrm{~mm}$ in clone CIP 302290.11 to $59.45 \mathrm{~mm}$ in clone CIP 302306.36 and the clone CIP 302288.14 with $61.30 \mathrm{~mm}$ (Table 2, 3 and Figure 1). All the clones had tuber sizes within recommended range for crisps $(40-60 \mathrm{~mm}$ ) and french fries $(45 \mathrm{~mm} \leq)$ (OOKO \& KABIRA 2011). Tubers larger than $60 \mathrm{~mm}$ in diameter yield crisps that are fragile and break easily during packaging and transportation (ABONG et al. 2010).

Table 2. Mean squares of the variance analysis of tuber size, dry matter, specific gravity, reducing sugars, and color.

\begin{tabular}{lccllll}
\hline $\begin{array}{l}\text { Source of } \\
\text { Variation }\end{array}$ & \multirow{2}{*}{ DF } & \multicolumn{5}{c}{ MS } \\
\cline { 3 - 7 } & & Tuber size & Dry matter & Specific gravity & Reducing sugars & Color \\
\hline Block & 2 & $40.17 \mathrm{NS}$ & $3.31 \mathrm{NS}$ & $12.92 \mathrm{NS}$ & $0.20 \mathrm{NS}$ & $0.05 \mathrm{NS}$ \\
Treatment & 16 & $817.46^{\star *}$ & $22.79^{\star *}$ & $1.74^{\star *}$ & $0.03^{* *}$ & $0.25^{\star *}$ \\
Error & 32 & 31.16 & 1.06 & 17.67 & 0.01 & 0.05 \\
Total & 50 & & & & & 1.59 \\
\hline Average & & 54.52 & 23.07 & 1.09 & 0.06 & 14.02 \\
CV $(\%)$ & & 20.38 & 4.25 & 10.34 & 5.02 & \\
\hline
\end{tabular}

$\mathrm{DF}=$ degrees of freedom; MS = mean squares; $\mathrm{CV}=$ coefficient of variation. $\mathrm{NS},{ }^{*},{ }^{* *}$ : not significant and significant at $\mathrm{p}<0.05$ and 0.01 , respectively.

The results were similar to those obtained by ABONG et al. (2010) who evaluating 24 potato cultivars including 18 varieties and 6 advanced potato clones for their suitability as raw materials for processing into potato crisps, show that the cultivars had a tuber diameter ranging from $43 \mathrm{~mm}$ and $56 \mathrm{~mm}$.

Dry matter: Dry matter varied significantly $(p<0.05)$ among the clones, ranging from $19.39 \%$ in CIP 302290.11 to $28.60 \%$ in clone CIP 302306.19 (Table 3, 4, and Figure 2). Good quality potato crisps processing or dehydrated products require tubers with dry matter content of greater or equal to $20 \%$ (MARWAHA et al. 2010).

The results obtained agree with ELFNESH et al. (2011), who evaluating the chips processing quality of five improved potato cultivars, found that the varieties present dry matter ranging from $20.33 \%$ and $27.33 \%$.

The dry matter content is considered as the major quality factor for potato processing (ABU-ZINADA \& MOUSA 2015). If the dry matter content is too low, the french fries or crisps will be too soft or too wet, and they will need more heat to fry to evaporate the water, if the dry matter content is too high, the finished products will be too hard and dry (KABIRA \& LEMAGA 2006). Higher tuber dry matter content results in better product recovery, lesser oil, and energy consumption because of relatively lesser time required for frying and better organoleptic quality with a longer shelf life of chips (SINGH et al. 2010).

KABIRA \& LEMAGA (2006) indicates that the potatoes with a dry matter content of $20-24 \%$ are ideal for making french fries, within this range we find the clones CIP 302285.31, CIP 302285.27, CIP 302290.23, CIP 302278.28, CIP 302288.42, CIP 302289.41, CIP 302304.27, CIP 302280.23, and CIP 302288.14. While those with a dry matter content higher than $24 \%$ are ideal for preparing crisps, within this range, we find the clones CIP 302288.39, CIP 302306.36, CIP 302295.32, CIP 302281.15, CIP 302288.33, and CIP 302306.19. Since some dry matter is lost during peeling, trimming, slicing, and blanching, the higher the initial content, the higher the amount that remains after frying (OGUNTOWO et al. 2016).

Specific gravity: There are significant differences between clones $(p<0.05)$ on the specific gravity, the clones varied from $1.072 \mathrm{~g} \mathrm{~cm}^{3}$ in clone CIP 302290.11 to $1.113 \mathrm{~g} \mathrm{~cm}^{3}$ in CIP 302288.35 (Table 3, 4, and Figure 2). Our findings were similar to those of ZAMAN et al. (2016), who conducted a research study on the 
assessment of fifteen selected genotypes based on biochemical characteristics ascertained that the genotypes were specific gravity of $1.060 \mathrm{~g} \mathrm{~cm}^{3}$ to $1.082 \mathrm{~g} \mathrm{~cm}^{3}$.

Table 3. Comparison of averages for tuber diameter, dry matter, specific gravity, reducing sugars, and color.

\begin{tabular}{llllll}
\hline Clone & Diameter $(\mathrm{mm})$ & $\begin{array}{l}\text { Dry } \\
\text { matter }(\%)\end{array}$ & $\begin{array}{l}\text { Specific } \\
\text { gravity } \\
\left(\mathrm{g} \mathrm{cm}^{-3}\right)\end{array}$ & $\begin{array}{l}\text { Reducing } \\
\text { sugars }(\%)\end{array}$ & Color \\
\hline CIP 302288.14 & $61.30 \mathrm{a}$ & $24.93 \mathrm{bcdef}$ & $1.099 \mathrm{a}$ & $0.043 \mathrm{~b}$ & $1.33 \mathrm{bc}$ \\
CIP 302306.36 & $59.45 \mathrm{a}$ & $25.19 \mathrm{bcde}$ & $1.105 \mathrm{a}$ & $0.061 \mathrm{~b}$ & $1.67 \mathrm{ab}$ \\
CIP 302285.31 & $58.32 \mathrm{ab}$ & $20.17 \mathrm{gh}$ & $1.078 \mathrm{~b}$ & $0.047 \mathrm{~b}$ & $1.50 \mathrm{abc}$ \\
CIP 302288.39 & $57.02 \mathrm{abc}$ & $25.05 \mathrm{bcde}$ & $1.101 \mathrm{a}$ & $0.038 \mathrm{~b}$ & $1.00 \mathrm{c}$ \\
CIP 302290.23 & $56.73 \mathrm{bc}$ & $21.83 \mathrm{fgh}$ & $1.083 \mathrm{ab}$ & $0.046 \mathrm{~b}$ & $1.83 \mathrm{ab}$ \\
CIP 302288.33 & $56.2 \mathrm{bcd}$ & $27.66 \mathrm{ab}$ & $1.112 \mathrm{a}$ & $0.039 \mathrm{~b}$ & $1.50 \mathrm{abc}$ \\
CIP 302295.32 & $55.32 \mathrm{bcde}$ & $26.49 \mathrm{abcd}$ & $1.107 \mathrm{a}$ & $0.036 \mathrm{~b}$ & $1.33 \mathrm{bc}$ \\
CIP 302278.28 & $54.70 \mathrm{cde}$ & $22.50 \mathrm{efgh}$ & $1.089 \mathrm{a}$ & $0.057 \mathrm{~b}$ & $2.00 \mathrm{a}$ \\
Amarilis INIA & $54.60 \mathrm{cde}$ & $20.30 \mathrm{gh}$ & $1.068 \mathrm{~b}$ & $0.230 \mathrm{a}$ & $2.50 \mathrm{a}$ \\
CIP 302288.35 & $54.45 \mathrm{cde}$ & $27.09 \mathrm{abcd}$ & $1.113 \mathrm{a}$ & $0.043 \mathrm{~b}$ & $1.50 \mathrm{abc}$ \\
CIP 302304.27 & $54.22 \mathrm{de}$ & $24.14 \mathrm{def}$ & $1.098 \mathrm{a}$ & $0.049 \mathrm{~b}$ & $1.67 \mathrm{ab}$ \\
CIP 302306.19 & $53.83 \mathrm{def}$ & $28.60 \mathrm{a}$ & $1.106 \mathrm{a}$ & $0.062 \mathrm{~b}$ & $1.83 \mathrm{ab}$ \\
CIP 302281.15 & $53.66 \mathrm{def}$ & $27.37 \mathrm{abc}$ & $1.104 \mathrm{a}$ & $0.071 \mathrm{~b}$ & $1.83 \mathrm{ab}$ \\
CIP 302289.41 & $52.08 \mathrm{def}$ & $24.08 \mathrm{def}$ & $1.087 \mathrm{a}$ & $0.038 \mathrm{~b}$ & $1.50 \mathrm{abc}$ \\
CIP 302280.23 & $51.02 \mathrm{efg}$ & $24.32 \mathrm{cdef}$ & $1.090 \mathrm{a}$ & $0.047 \mathrm{~b}$ & $1.33 \mathrm{bc}$ \\
CIP 302285.27 & $50.80 \mathrm{efg}$ & $20.29 \mathrm{gh}$ & $1.079 \mathrm{~b}$ & $0.052 \mathrm{~b}$ & $1.83 \mathrm{ab}$ \\
CIP 302288.42 & $49.01 \mathrm{fg}$ & $23.09 \mathrm{efg}$ & $1.083 \mathrm{ab}$ & $0.049 \mathrm{~b}$ & $1.00 \mathrm{c}$ \\
CIP 302290.11 & $48.70 \mathrm{~g}$ & $19.39 \mathrm{~h}$ & $1.072 \mathrm{~b}$ & $0.051 \mathrm{~b}$ & $1.50 \mathrm{abc}$ \\
\hline
\end{tabular}

Average with the same letter is not significantly different according to Duncan at $5 \%$.

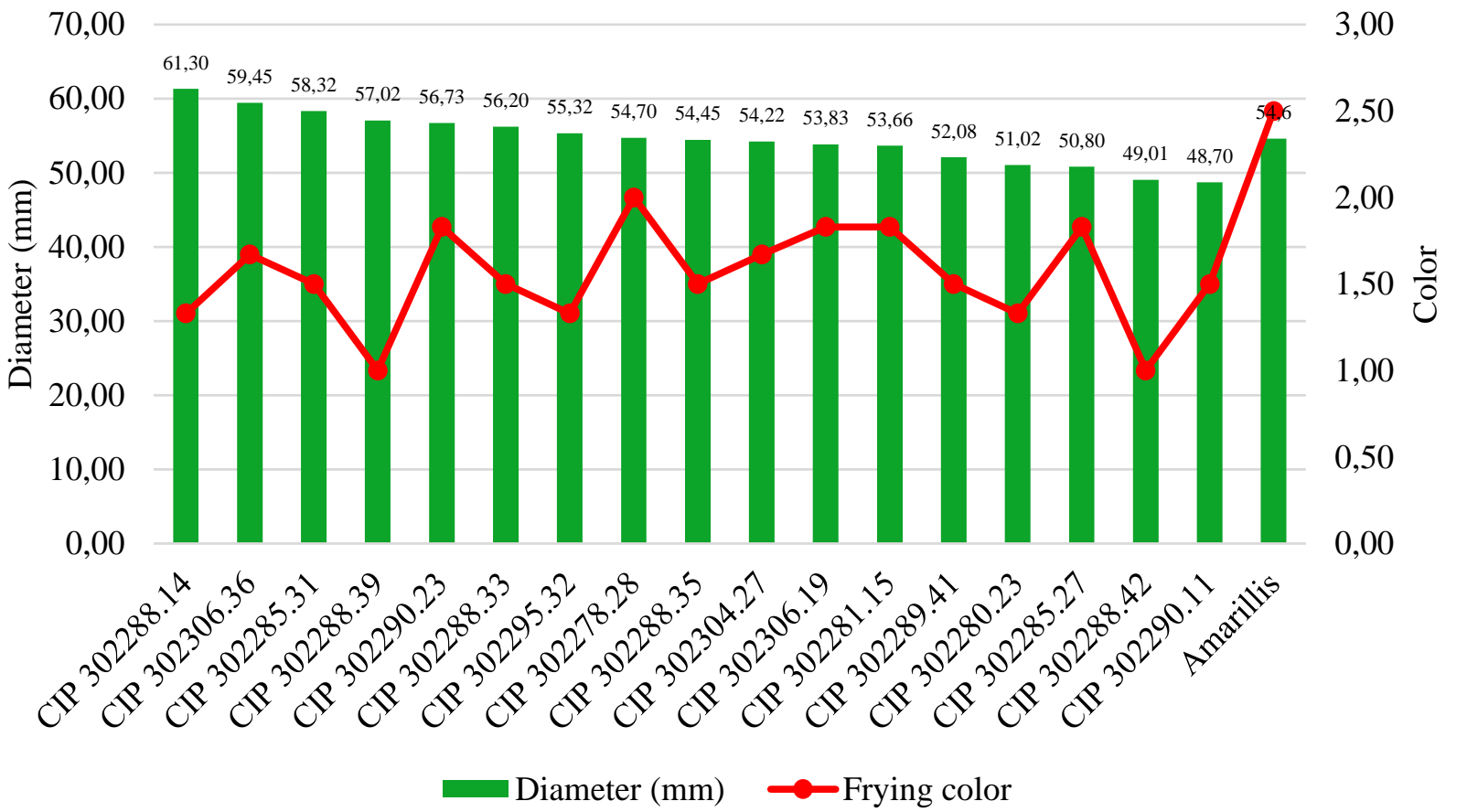

Figure 1. Graph of the result in tuber diameter, and color in 17 advanced potato clones and 1 commercial variety in Cajamarca, Peru.

ABU-ZINADA \& MOUSA (2015) categorized tuber specific gravity values as low $(<1.077)$, intermediate (between 1.077 and 1.086) and high (>1.086). Accordingly, tubers of clones CIP 302290.11 (1.072) and variety Amarilis INIA (1.071) had the lowest values. The clones CIP 302285.31 (1.078), CIP 302285.27 (1.079), CIP 302288.42 (1.083), and CIP 302290.23 (1.083) are within an intermediate group indicating that 
they are fit for processing. Finally, the clones with high specific gravity (more than 1.086) were CIP 302289.41 (1.087), CIP 302278.28 (1.089), CIP 302280.23 (1.090), CIP 302304.27 (1.098), CIP 302288.14 (1.099), CIP 302288.39 (1.101), CIP 302306.36 (1.105), CIP 302306.19 (1.106), CIP 302295.32 (1.107), CIP 302288.33 (1.112), and CIP 302288.35 (1.113).

Potato crisps processing requires tubers with a specific gravity greater or equal to $1.080 \mathrm{~g} \mathrm{~cm} 3$ (ABONG et al. 2010). High specific gravity is an indication that the raw potatoes will produce high chip volume due to high dry matter content (ELFNESH et al. 2011).

Potato tuber specific gravity and dry matter content are very important characteristics in determining the suitability of cultivars for crisps (ABONG et al. 2010).

Reducing sugars: In all the clones, there were significant $(p<0.05)$ difference in levels of reducing sugar content, ranging from $0.036 \%$ in clone CIP 302295.32 to $0.071 \%$ in clone CIP 302281.15 (Table 3,4 , and Figure 2), however, Amarilis variety exceeded this range obtaining a value of $0.23 \%$. These results agree to those reported by ABONG et al. (2010) who found a similar range with $0.07 \%$ to $0.4 \%$.

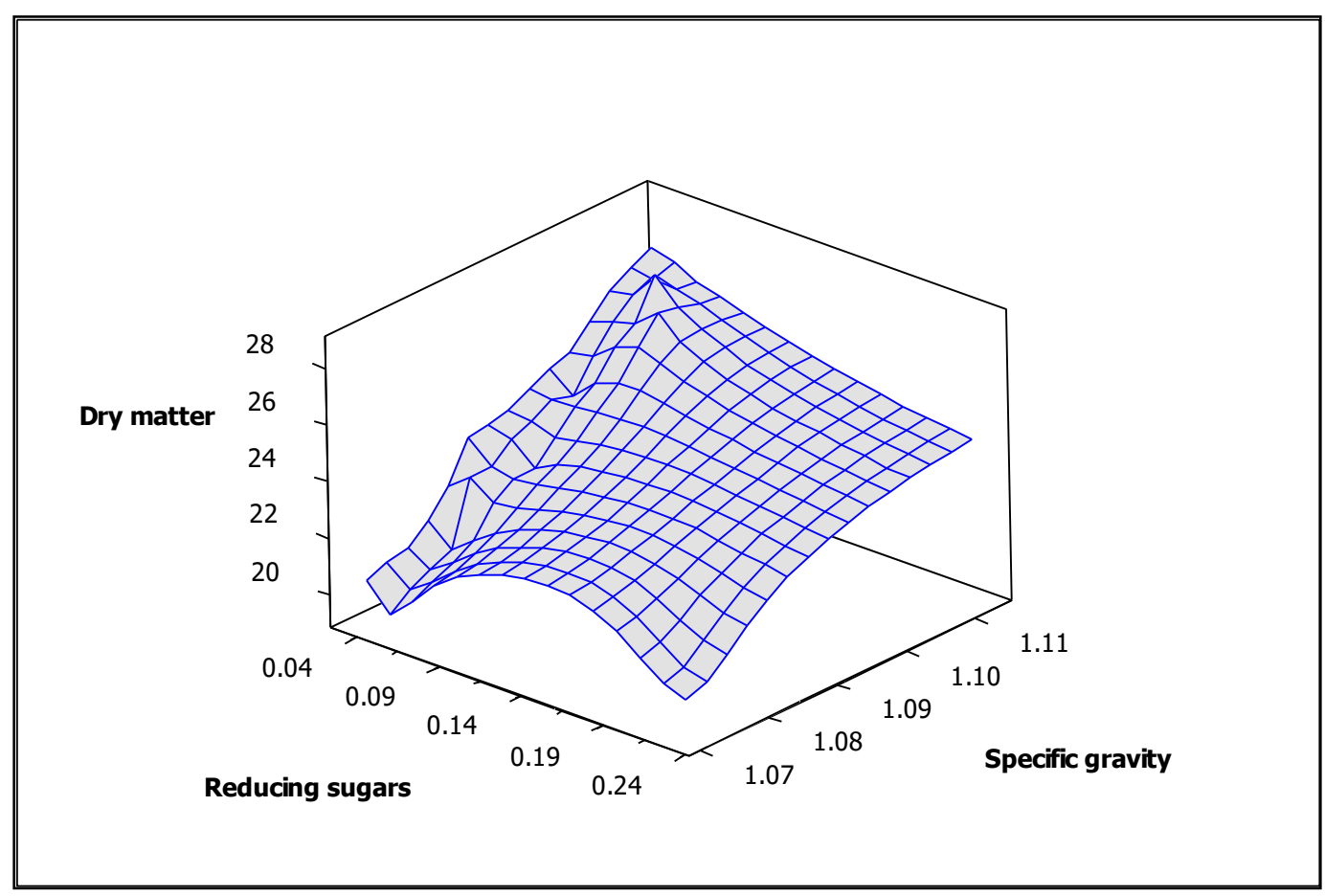

Figure 2. Graph of the result in dry matter, specific gravity, reducing sugars in 17 advanced potato clones in Cajamarca, Peru.

For producing good quality fried or dehydrated products, potatoes should have low reducing sugars ( $<0.1 \%$ on fresh weight basis), and the reducing sugar content may not exceed $0.2-0.3 \%$ of the fresh weight (MARWAHA et al. 2010). When the reducing sugar level of raw potatoes is high, this could lead to undesirable dark color after frying (KAUR et al. 2008). The higher the content of reducing sugars, the darker the frying color and it is responsible for the browning of potato chips, and it has implications in acrylamide formation (HALFORD et al. 2012). Therefore, potatoes destined for making chips, french fries, and other fried products, need to have low sugar content to avoid browning of the finished product (KUMAR et al. 2004).

Color: Significant $(p<0.05)$ clone differences in color of crisps and french fries were noted, ranging from 1 in CIP 302288.42 and CIP 302288.39 to 2.00 in clone CIP 302278.28 and in Amarilis variety with 2.5 (Table 3, 4, and Figure 1). A similar result was also presented by ELFNESH et al. (2011), who studied the processing quality of improved potato cultivars as influenced by growing environment, indicated that the color of all cultivars ranges between 1 and 2 where 1 is light color and 2 is light tan which is commercially

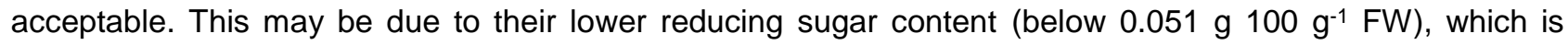
suitable to produce commercially acceptable chip color.

PEDRESCHI et al. (2016) indicates that the color of potato chips is the first quality parameter evaluated by consumers and is critical in the acceptance of the product worth noting, acrylamide has been reported as a critical compound for human health (carcinogenic in rats) that is formed in potatoes during frying and that is highly related to the color of the potato chips. 


\section{CONCLUSION}

The clones were found to have good physical tuber qualities (tuber shape, eye depth, skin color).

Tuber sizes ranging from the clones CIP 302290.11 to clone CIP 302306.36, most had tuber sizes within recommended range for crisps $(40-60 \mathrm{~mm})$ and french fries $(45 \mathrm{~mm} \leq)$ except for the clone CIP 302288.14. Acceptable dry matter content for crisps and french fries ranges from PIC clones 302290.11 to clone CIP 302306.19, and specific gravity of the clones varied from clone CIP 302290.11 to CIP 302288.35. Reducing sugar levels ranged between the clone CIP 302295.32 to clone CIP 302281.15 and commercially acceptable chip color in most the clones.

Most of the advanced clones except for clone CIP 302290.11 were found to be suitable for processing into french fries.

The clone CIP 302306.19 had the highest results regarding the quality of potato tubers.

The clone CIP 302289.41 reported the highest value of dry matter contents of $24.08 \%$, specific gravity of 1.087 , reducing sugar of $0.038 \%$, and commercially acceptable chip color demonstrating to be a good raw material not only for french fries but also acceptable for chips in Peru.

\section{ACKNOWLEDGEMENTS}

To the Association for the Conservation and Improvement of High Andean Biodiversity - ACOMEBIO, Convention No. 176-FINCyT-FIDECOM-PIPEI-2012.

\section{REFERENCES}

ABBAS $G$ et al. 2012. Determination of processing and nutritional quality atributes of potato genotypes in Pakistan. Pakistan Journal of Botany 44: 201-208.

ABONG GO et al. 2010. Evaluation of selected Kenyan potato cultivars for processing into potato crisps. Agriculture and Biology Journal of North America 1: 886-893.

ABU-ZINADA IA \& MOUSA WA 2015. Growth and productivity of different potato varieties under Gaza Strip conditions. International Journal of Agriculture and Crop Sciences 8: 433-437.

ARKOUB DL 2016. Influence of the Thermal Processing on the Physico-Chemical Properties and the Antioxidant Activity of a Solanaceae Vegetable: Eggplant. Journal of Food Quality 39: 181-191.

BANDANA SV et al. 2016. Variation in biochemical parameters in different parts of potato tubers for processing purposes. Journal of Food Science and Technology 53: 2040-2046.

ELFNESH F. et al. 2011. Processing quality of improved potato (Solanum tuberosum L.) cultivars as influenced by growing environment and blanching. African Journal of Food Science 5: 324-332.

FREITAS ST et al. 2012. Processing quality of potato tubers produced during autumn and spring and stored at different temperatures. Horticultura Brasileira 30: 91-98.

GIUSTI MM et al. 2014. Characterization and Quantitation of Anthocyanins and Other Phenolics in Native Andean Potatoes. Journal of Agricultural and Food Chemistry 62: 4408-4416.

HALFORD NG et al. 2012. Concentrations of Free Amino Acids and Sugars in Nine Potato Varieties: Effects of Storage and Relationship with Acrylamide Formation. Journal of Agricultural and Food Chemistry 60: 12044-12055.

KABIRA JN \& LEMAGA B. 2006. Potato processing: quality evaluation procedures for research and food industries applications in East and Central Africa. Kenya Agricultural Research 5: 12-19.

KITA A et al. 2015. Antioxidant activity and quality of red and purple flesh potato chips. Food Science and Technology 62: 525-531.

KUMAR D et al. 2004. An overview of the factors affecting sugar content of potatoes. Annals of Applied Biology 145 : 247-256.

LI XQ et al. 2005. Inheritance and genetic mapping of tuber eye depth in cultivated diploid potatoes. Theoretical and Applied Genetics 110: 1068-73.

MARWAHA RS et al. 2010. Potato processing scenario in India: Industrial constraints, future projections, challenges ahead and remedies - A review. Journal of Food Science and Technology 47: 137-156.

MORI M et al. 2010. Anthocyanins from Skins and Fleshes of Potato Varieties. Food Science and Technology Research 16: $115-122$.

OGUNTOWO et al. 2016. Effects of processing and storage conditions of cocoyam strips on the quality of fries. Food Science \& Nutrition 4: 906-914.

OOKO GA \& KABIRA JA. 2011. Suitability of three newly released potato varieties for processing into crisps and French fries. African Journal of Food, Agriculture, Nutrition and Development 11: 5266-5281.

PEDRESCHI F et al. 2016. Quality Evaluation and Control of Potato Chips. In: DA-WEN S. (Ed.) Computer Vision Technology for Food Quality Evaluation. 2.ed. Dublin: Academic Press. p. 591-613.

SINGH SV et al. 2010. Kufri Frysona: First high yielding potato variety for French fries in India. Potato Journal 37: 103109.

SOLAIMAN AHM et al. 2015. Yield, dry Matter, specific gravity and color of three Bangladeshi local potato cultivars as influenced by stage of maturity. Journal of Plant Sciences 10: 108-115. 
THOMAS A \& THOMAS A 2014. Acrylamide - A Potent Carcinogen in Food. International Journal of Science and Research 3: 177-188.

TING S. 1956. Rapid colometric methods of simultaneus determinations of total reducing sugar and fructose in citrus juice. Journal of Agricultural and Food Chemistry 4: 263- 266.

ZAMAN S et al. 2016. Assessment of fifteen selected potatoes (Solanum tuberosum L.) genotypes on the basis of biochemical characteristics. International Journal of Biology, Pharmacy and Allied Sciences 5: 725-735.

ZHANG Y et al. 2009. Genetic analysis of pigmented tuber flesh in potato. Theoretical and Applied Genetics 119: 143150.

ZHANG H et al. 2017. Progress of potato staple food research and industry development in China. Journal of Integrative Agriculture 16: 2924-2932. 